Provided for non-commercial research and education use. Not for reproduction, distribution or commercial use.



This article appeared in a journal published by Elsevier. The attached copy is furnished to the author for internal non-commercial research and education use, including for instruction at the author's institution and sharing with colleagues.

Other uses, including reproduction and distribution, or selling or licensing copies, or posting to personal, institutional or third party websites are prohibited.

In most cases authors are permitted to post their version of the article (e.g. in Word or Tex form) to their personal website or institutional repository. Authors requiring further information regarding Elsevier's archiving and manuscript policies are encouraged to visit:

http://www.elsevier.com/authorsrights 


\title{
Early coronary calcifications are related to cholesterol burden in heterozygous familial hypercholesterolemia
}

\author{
Antonio Gallo, MD*, Philippe Giral, MD, PhD, Alain Carrié, MD, PhD, \\ Valérie Carreau, MD, Sophie Béliard, MD, PhD, Randa Bittar, PharmD, \\ Marianna Maranghi, MD, PhD, Marcello Arca, MD, Philippe Cluzel, MD, PhD, \\ Alban Redheuil, MD, PhD, Eric Bruckert, MD, PhD, David Rosenbaum, MD, PhD
}

Unité de Prévention Cardiovasculaire, Service d'Endocrinologie-Métabolisme, Assistance Publique/Hôpitaux de Paris, Groupe Hospitalier Pitié-Salpêtrière - Université Pierre et Marie Curie, Paris, France (Drs Gallo, Giral, Carreau, Bruckert, and Rosenbaum); Sorbonne Universités, UPMC Université Paris 06, INSERM 1146, CNRS 7371, Laboratoire d'imagerie Biomédicale, Paris, France (Drs Gallo, Cluzel, Redheuil, and Rosenbaum); Atherosclerosis Research Unit, Diabetes and Cardiovascular Prevention Unit, Department of Internal Medicine and Medical Specialties, Policlinico Umberto I, "Sapienza" University of Rome, Rome, Italy (Drs Gallo, Maranghi, and Arca); Dyslipoproteinemia and Atherosclerosis Research Unit, UMRS 939, National Institute for Health and Medical Research (INSERM) and Pierre et Marie Curie University (UPMC - Paris VI), Paris, France (Drs Giral and Bruckert); Molecular and Chromosomic genetic Center, INSERM U939; Assistance Publique/Hôpitaux de Paris, Groupe Hospitalier Pitié-Salpêtrière, Paris, France (Dr Carrié); Service de Nutrition, Maladies métaboliques et Endocrinologie, Hôpital Conception, Marseille, France (Dr Béliard); Biochemistry Functional Unit for Metabolic Disease Assistance Publique/Hôpitaux de Paris, Groupe Hospitalier Pitié-Salpêtrière, Paris, France (Dr Bittar); Département d'imagerie cardiovasculaire et de radiologie interventionnelle, Pôle Imagerie - Groupe Hospitalier Pitié-Salpêtrière, Assistance Publique-Hôpitaux de Paris, Paris, France (Drs Cluzel and Redheuil); and Imaging Core Lab, Institute of Cardiometabolism and Nutrition, ICAN, Paris, France (Drs Cluzel, Redheuil, and Rosenbaum)

\author{
KEYWORDS: \\ Familial \\ hypercholesterolemia; \\ Cardiovascular disease \\ prevention; \\ Calcium score; \\ Coronary artery \\ calcification; \\ Cholesterol burden
}

BACKGROUND: The identification of high-risk patients with heterozygous familial hypercholesterolemia $(\mathrm{HeFH})$ that may benefit from early treatment is challenging. Coronary Artery Calcification (CAC) score accounts for coronary atherosclerotic burden. It has proven its accuracy in cardiovascular risk assessment in the general population but data in $\mathrm{HeFH}$ are lacking.

OBJECTIVE: The aim of our study was to assess CAC prevalence and its relationship with lifelong cholesterol exposure, calculated by total cholesterol burden (TCB) in patients with HeFH.

METHODS: A total of $112 \mathrm{HeFH}$ patients (50\% males, median age 45 years) regularly followed-up since diagnosis were prospectively recruited at Pitié-Salpêtrière Hospital, Paris, France. CAC score was assessed using noncontrast multi-detector computed tomography. TCB was calculated as total cholesterol (TC) $\times$ age at diagnosis plus annually assessed TC.
* Corresponding author. Unité de Prévention Cardiovasculaire, Service d'Endocrinologie Métabolisme, Groupe Hospitalier Pitié-Salpêtrière, Assistance Publique Hôpitaux de Paris, 83, boulevard de l'Hôpital, Paris Cedex 13 75651, France.
E-mail address: antoniogallo.md@gmail.com

Submitted October 24, 2016. Accepted for publication March 27, 2017. 
RESULTS: The prevalence of CAC was 58\%. Patients without CAC showed lower TCB than patients with CAC $(298 \pm 110$ vs $417.9 \pm 89$ mmol-years $/ \mathrm{L}, P<.001)$. Among patients aged $<45$ years $(n=56), 39 \%$ exhibited CAC and a higher TCB compared with patients without CAC $(352 \pm 71$ vs $255 \pm 88$ mmol-years/L, $P<.001)$ due to higher TC levels at diagnosis $(10.2 \pm 2$ vs $8.7 \pm 2 \mathrm{mmol} / \mathrm{L}, P=.01)$. Multivariate analysis indicated that TCB was independently associated to $\mathrm{CAC}$.

CONCLUSIONS: Asymptomatic HeFH subjects exhibit early coronary atherosclerosis directly associated with TCB burden. CAC score may be useful to identify higher risk HeFH patients who can benefit from earlier and more aggressive treatment.

(C) 2017 National Lipid Association. All rights reserved.

\section{Introduction}

In Western countries, one over 200 people is affected by heterozygous familial hypercholesterolemia $(\mathrm{HeFH}){ }^{1,2}$ In this autosomal dominant genetic disorder, the early and prolonged elevation of atherogenic lipoprotein particles triggers the development of premature coronary artery disease $(\mathrm{CAD})^{3}$; nevertheless, HeFH phenotype varies among patients, some being more severe than others. ${ }^{4}$ The identification of $\mathrm{HeFH}$ patients at high cardiovascular risk (CVR) is crucial for early treatment initiation as a 100-fold increase in coronary heart disease (CHD) risk has been observed in 20- to 39-years-old untreated HeFH patients. ${ }^{5}$ As recently pointed out, the characterization of severe $\mathrm{FH}$ phenotypes is crucial for targeting a more aggressive treatment since younger age. ${ }^{6}$ Common risk score calculators are inadequate as they underestimate $\mathrm{FH}$ young patients CVR by not accounting for lifelong elevated cholesterol levels. Furthermore, currently recommended imaging techniques for the detection of asymptomatic atherosclerosis suffer from various drawbacks limiting their applicability in young populations.

Coronary artery calcium (CAC) score measures atherosclerotic burden and predicts cardiovascular events in young patients and in patients with familial history of cardiovascular disease. ${ }^{7,8}$ Lifelong exposure to cholesterol can be estimated by the addition of yearly-obtained total cholesterol (TC) levels to calculate total cholesterol burden (TCB).

Our aim was to use CAC score to evaluate coronary atherosclerotic burden in patients with genetically diagnosed $\mathrm{HeFH}$ and to study the relationship between CAC and TCB.

\section{Methods}

\section{Study population}

Patients were consecutively recruited between May and December 2015 at the Cardiovascular Prevention Unit at Pitié-Salpêtrière Hospital in Paris, France.

Inclusion criteria were genetically confirmed $\mathrm{HeFH}$, age between 20 and 60 years, no symptoms or electrocardiographic signs of ischemia, no personal history of CHD, regular follow-up since diagnosis. Exclusion criteria were no affiliation to a health care system, informed consent refusal, contraindication to computed tomography (CT), personal history of cardiovascular disease and myocardial infarction, diabetes mellitus, uncontrolled hypertension or triglycerides $(\mathrm{TGs})>4.5 \mathrm{mmol} / \mathrm{L}$. We included only index cases; relatives were excluded. The local institutional review board approved the study and informed consent was obtained from all included patients.

\section{CAC measurements}

Each patient underwent a multi-detector CT scan (Definition Flash, Siemens, Erlangen, Germany) for a total radiation exposure of 1 to $3 \mathrm{mSv}$. Coronary arteries were imaged without contrast using helicoidal CT with prospective electrocardiographic gating. Monophasic mesodiastolic imaging ( $75 \%$ of cardiac cycle) was performed when the heart rate was under $85 \mathrm{bpm}$ and replaced by systolic imaging ( $40 \%$ of cardiac cycle) when heart rate was more than $85 \mathrm{bpm}$ to avoid right coronary artery motion artifacts. Radiation dose was automatically adjusted to patient morphology scout. Default voltage was $100 \mathrm{kV}$ and $120 \mathrm{kV}$ in overweight patients, and tube current was automatically adapted according to patient morphology (average 100-200 mAs) to minimize radiation dose. Slice thickness reconstruction was $0.75 \mathrm{~mm}$ every $0.7 \mathrm{~mm}$. Typical total breath-holding time was from 10 to 15 seconds. CAC was quantified by means of the previously described Agatston scoring method. ${ }^{9}$ The presence of CAC was evaluated by semiautomated calcium scoring software SyngoVia (Siemens, Erlangeen, Germany) over the entire epicardial coronary tree. Briefly, coronary calcium was defined as a lesion above a threshold of 130 Hounsfield units, with an area of $\geq 3$ adjacent pixels (at least $1 \mathrm{~mm}^{2}$ ). The CAC score was computed from the product of the attenuation factor and the area of calcification (square millimeter), with the total CAC score of each coronary artery being equal to the sum CAC of all calcified plaques from that artery. The total calcium score was calculated by summing CAC scores from the left main, left anterior descending, left circumflex, and right coronary arteries. All CT scans were quantified in an expert central reading 
center and supervised by a senior cardiovascular radiologist (A.R.) who was blinded to patients FH status and TCB.

\section{TCB calculation}

Lifelong cholesterol exposure was calculated as TCB (mmol-years/L) according to Schmidt et al. ${ }^{10}$ TCB is the addition of cholesterol burden at diagnosis (dCB) and post-diagnosis cholesterol burden (pdCB). dCB was obtained by multiplying the initial serum TC value (before treatment initiation) by the age of the patient at diagnosis. pdCB was calculated by adding the TC values annually measured during follow-up (on statin treatment) using patients' medical records. For patients who were already on treatment when genetic diagnosis was obtained, TCB was calculated by multiplying the highest TC value before the onset of statin treatment by patient's age at clinical diagnosis. Missing TC values during follow-up were replaced by the mean of all available TC values.

\section{Risk factors assessment}

Body mass index was measured as weight (kilograms) divided by measured height (meters squared). Arterial hypertension was defined as systolic blood pressure (SBP) $\geq 140 \mathrm{~mm} \mathrm{Hg}$, diastolic blood pressure (DBP) $\geq 90 \mathrm{~mm} \mathrm{Hg}$, and/or use of antihypertensive medication. Diabetes mellitus was defined as fasting plasma glucose (FPG) levels $\geq 7.0 \mathrm{mmol} / \mathrm{L}$ or $\mathrm{HbA}_{1 \mathrm{C}}>6.5 \%$ and/or use of antidiabetic treatment. Current smoking was defined as having smoked at least 1 cigarette in the last 30 days.

\section{Statistical analysis}

Data are reported as mean \pm standard deviation (SD) for continuous parametric and median (interquartile range) for continuous nonparametric variables, and as frequency (percentage) for categorical variables. Normality of continuous variables distribution was tested using Shapiro-Wilk's test. Differences between groups were evaluated by analysis of variance. Distribution of categorical variables between groups was evaluated using the chi-square test. Correlations between 2 variables were assessed using a linear regression model and Pearson's correlation coefficient (r) or Spearman's rho (for nonparametric variables) were provided. CAC score was further studied for its associations with TCB, SBP, sex (male = 1), FPG, highdensity lipoprotein cholesterol (HDL-C), TG, smoking status (current smoking $=1$ ), and statin treatment (yes $=1$ ) using multivariate regression model. Age was not considered separately as already included in the TCB equation. The cubic root of CAC score was used for parametrical tests. ${ }^{10}$ Study population was stratified by age according to median age of 45 years. Statistical analyses were performed using SAS software and a $P$ value $<.05$ was considered significant.

\section{Results}

Table 1 summarizes the main clinical and biochemical characteristics of the 112 patients, according to gender. Mean time between age of HeFH diagnosis and CT scan was 25 years and $82.1 \%$ of patients were under statin treatment. Median overall CAC score was $9.1(0-148)$ and males had a higher CAC score compared with females (median 59.7 vs 0.0 , respectively, $P<.01$ ). The overall prevalence of CAC was $58.1 \%$, being higher in males than in females $(P=.04)$. No differences were found between genders in terms of age, TCB, body mass index as well as xanthomas, mutation type, smoke, and hypertension prevalence. Higher TC, HDL-C, and apolipoprotein-A1 levels, as well as lower TG were observed in females, whereas a higher proportion of males were under lipidlowering treatment.

Main characteristics of the study population, stratified by presence or absence of CAC, are shown in Table 2 . Patients with CAC exhibited higher TCB than patients without CAC (417.9 \pm 89 vs $298.0 \pm 110$ mmol-years/L, $P<.001)$. Patients with CAC were more likely to be males and older, with a higher prevalence of xanthomas and hypertension. At diagnosis, they also presented with a higher age and TC. Compared with patients without CAC, they had higher Low-density lipoprotein (LDL) cholesterol (LDL-C; $P<.05)$, TC, Apo-B, and TG $(P<.02)$ levels. Among patients with LDL receptor (LDLR) mutations, $47(45.2 \%)$ had a null mutation, and $57(54.8 \%)$ a defective mutation. No differences were found in CAC prevalence according to the residual LDLR function. Lipoprotein(a) was not associated with TCB or CAC, either as a dichotomous and a continuous variable.

TBC was significantly related with all 3 commonly used scores for clinical diagnosis of FH (Dutch Lipid Clinic Network, Simon-Broome, or Make Early Diagnosis to Prevent Early Deaths), even though the Simon-Broome showed the strongest association $\left(R^{2}=0.645, P=.00001\right.$; Supplementary Table 1). Conversely, the CAC score levels were significantly associated only with Dutch Lipid Clinic Network scores $\left(R^{2}=0.193, P=.014\right)$ in a model that included age.

Noteworthy, according to all 3 CVR scores, the cohort was at low risk (median [interquartile range], SCORE $0.0 \%$ [0.0-1.1]; Framingham 2.1\% [0.375-6.05]; atherosclerotic cardiovascular disease $2.2 \%$ [1.0-4.9]). CAC was present in about half of patients identified as low CVR by common CVR equations (Supplementary Table 2). To this regard, about $20 \%$ of $\mathrm{HeFH}$ patients classified as at low-risk patients had CAC $>100$. This was observed also in the young subgroup (Supplementary Table 3).

When stratified according to the median age of 45 years, patients aged $<45$ years exhibited a $39 \%$ prevalence of CAC (Fig. 1).

Furthermore, HeFH patients aged $<45$ years with CAC had a higher $\mathrm{dCB}$ and TCB compared with patients without $\mathrm{CAC}$ in the same age range (Fig. 2). 
Table 1 Patient characteristics according to gender

\begin{tabular}{|c|c|c|c|}
\hline & All $(n=112)$ & Males $(n=56)$ & Females $(n=56)$ \\
\hline Age, $y$ & $44.5(38-52)$ & $44(36-51)$ & $46.5(38-55)$ \\
\hline BMI $\left(\mathrm{kg} / \mathrm{m}^{2}\right)$ & $24.4(21-27)$ & $25.4(23-28)$ & $23.4(20-27)$ \\
\hline \multicolumn{4}{|l|}{ Subclinical atherosclerosis burden } \\
\hline CAC score $0, n(\%)$ & $58(51.8)$ & $23(41.1)$ & $35(62.5)^{\ddagger}$ \\
\hline CAC score $1-100, n(\%)$ & $22(19.6)$ & $10(17.8)$ & $12(21.4)$ \\
\hline $\mathrm{CAC}>100, n(\%)$ & $32(28.6)$ & $23(41.1)$ & $9(16.1)^{*}$ \\
\hline \multicolumn{4}{|l|}{ Cholesterol burden } \\
\hline Cholesterol burden at diagnosis, mmol-years/L & $187.6 \pm 118$ & $186.9 \pm 134$ & $188.4 \pm 100$ \\
\hline Cholesterol burden postdiagnosis, mmol-years/L & $182.0 \pm 87$ & $175.3 \pm 87$ & $188.7 \pm 88$ \\
\hline Total cholesterol burden, mmol-years/L & $363.7 \pm 114$ & $359.6 \pm 132$ & $374.5 \pm 94$ \\
\hline \multicolumn{4}{|l|}{ FH history } \\
\hline Mutation type (LDLR/ApoB/PCSK9; $n$ ) & $104 / 7 / 1$ & $51 / 4 / 1$ & $53 / 3 /-$ \\
\hline Age of diagnosis, $y$ & $18.0(11-27)$ & $16(10-29)$ & $18(12-23)$ \\
\hline $\mathrm{TC}$ at diagnosis, mmol/L & $9.6(8-11)$ & $9.0(7.9-11.6)$ & $9.8(8.3-10.6)$ \\
\hline Xanthomas, $n(\%)$ & $27(24.1)$ & $13(23.2)$ & $14(25)$ \\
\hline \multicolumn{4}{|l|}{ Cardiovascular risk factors } \\
\hline Current smoking, $n(\%)$ & $34(30.4)$ & $19(34)$ & $15(26.7)$ \\
\hline Arterial hypertension, $n(\%)$ & $11(9.8)$ & $7(12.5)$ & $4(7.1)$ \\
\hline \multicolumn{4}{|l|}{ Lipid profile } \\
\hline $\mathrm{TC}, \mathrm{mmol} / \mathrm{L}$ & $6.2(5-7)$ & $5.6(5-6.6)$ & $6.6(6-7)^{\ddagger}$ \\
\hline $\mathrm{TG}, \mathrm{mmol} / \mathrm{L}$ & $1.0(0.7-1.3)$ & $1.1(1-1.5)$ & $0.9(0.7-1.3)^{*}$ \\
\hline HDL-C, mmol/L & $1.3(1-1.6)$ & $1.2(1-1.4)$ & $1.5(1-2)^{\S}$ \\
\hline LDL-C, mmol/L & $4.1(3.6-5)$ & $3.9(4-5)$ & $4.2(4-5.5)$ \\
\hline $\mathrm{ApoB}, \mathrm{mg} / \mathrm{dL}$ & $116.0(103-137)$ & $116.0(101.5-137)$ & $117.0(103-214)$ \\
\hline ApoA1, mg/dL & $145.0(131-163)$ & $140.0(126-152)$ & $149.5(137-166)^{*}$ \\
\hline $\operatorname{Lp}(a), \mathrm{mg} / \mathrm{dL}$ & $26.0(12-51)$ & $21.5(9-45)$ & $27.0(13-53)$ \\
\hline \multicolumn{4}{|l|}{ Current lipid-lowering treatment } \\
\hline Overall, $n(\%)$ & $92(82.1)$ & $53(94.6)$ & $39(69.6)^{*}$ \\
\hline Statins, $n(\%)$ & $90(80.3)$ & $52(92.8)$ & $38(67.8)^{*}$ \\
\hline Ezetimibe, $n(\%)$ & $38(33.9)$ & $24(42.8)$ & $14(25)^{\dagger}$ \\
\hline
\end{tabular}

ApoA1, apolipoprotein A1; ApoB, apolipoprotein B; BMI, body mass index; CAC, coronary artery calcium; FH, familial hypercholesterolemia; HDL-C, high-density lipoprotein cholesterol; LDL-C, low-density lipoprotein cholesterol; LDL-R, low-density lipoprotein cholesterol receptor; Lp(a), lipoprotein (a); SBP, systolic blood pressure; TC, total cholesterol; TG, triglycerides.

Data are expressed as mean \pm standard deviation or median (interquartile range). ${ }^{*} P<.01 ;{ }^{\dagger} P<.05 ;{ }^{\ddagger} P<.02 ;{ }^{\S} P<.001$; males vs female.

Cholesterol burden at diagnosis was calculated as age $\times$ TC at diagnosis; Cholesterol burden postdiagnosis was calculated as the sum of one value of TC per year since diagnosis; Total cholesterol burden is the sum of cholesterol burden at diagnosis and cholesterol burden postdiagnosis.

The higher $\mathrm{dCB}$ was explained by higher $\mathrm{TC}$ at diagnosis $(10.2 \pm 2$ vs $8.7 \pm 2 \mathrm{mmol} / \mathrm{L}, P=.01)$ while age at diagnosis was not different (11 vs 15 years, $P=.09$ ). Postdiagnosis $\mathrm{CB}$ was not different between the 2 subgroups. No differences in $\mathrm{TCB}, \mathrm{dCB}$, and $\mathrm{pdCB}$ were found between patients aged $\geq 45$ years with $\mathrm{CAC}$ vs patients without CAC.

Univariate analysis showed that CAC presence was associated with TCB $\left(R^{2}=0.330, P<.001\right)$, pdCB $\left(R^{2}=0.248, P<.001\right)$, and $\mathrm{dCB}$ (adjusted $R^{2}=0.156$, $P=.001)$. When considered separately, both age and TCB were found to be positively correlated to CAC (Spearman's rho $=0.462$ and 0.500 , respectively. $P<.001$ ). Multivariate analysis (Table 3) indicated that TCB was associated to CAC score levels independently from gender, smoking status, statin treatment, HDL-C, TG, FPG, and SBP levels $(P<.001)$.

\section{Discussion}

In this study, asymptomatic genetically determined $\mathrm{HeFH}$ patients were found to have a high prevalence of CAC. Lifelong cholesterol accumulation, measured by the $\mathrm{TCB}$, was independently associated to this premature CAC detection.

These findings are in line with 2 previous reports of early calcified coronary plaques in clinically diagnosed $\mathrm{HeFH}$ evaluated by electron-beam tomography ${ }^{11}$ and CT scan. ${ }^{12}$ In the latter study, the prevalence of $\mathrm{HeFH}$ patients with CAC was below $50 \%$, which is comparable to our results.

Presence of CAC has been associated to a higher risk of CHD in asymptomatic patients with dyslipidemia ${ }^{13}$ or with family history of CHD. ${ }^{8}$ The prevalence of CAC in our cohort was much higher than that found in the CARDIA 
Table 2 Characteristics of patients with and without CAC

\begin{tabular}{|c|c|c|}
\hline & CAC $0(n=47)$ & $\mathrm{CAC}>0(n=65)$ \\
\hline Gender, $n$ male $/ n$ female & $18 / 29$ & $38 / 27^{*}$ \\
\hline Age, y & $38(28-46)$ & $48.5(43-53)^{\dagger}$ \\
\hline $\mathrm{BMI}, \mathrm{kg} / \mathrm{m}^{2}$ & $22.6(20-27)$ & $25.6(23-28)$ \\
\hline CAC score & 0 & $161.75(32-375)$ \\
\hline \multicolumn{3}{|l|}{ Cholesterol burden } \\
\hline Cholesterol burden at diagnosis, mmol-years/L & $145.5 \pm 111$ & $217.3 \pm 114^{\dagger}$ \\
\hline Cholesterol burden postdiagnosis, mmol-years/L & $155.6 \pm 78$ & $199.6 \pm 89^{\dagger}$ \\
\hline Total cholesterol burden, mmol-years/L & $298 \pm 110$ & $417.9 \pm 89^{\dagger}$ \\
\hline \multicolumn{3}{|l|}{ FH history } \\
\hline Mutation type (LDLR/ApoB/PCSK9), $n$ & $45 / 2 /-$ & $59 / 5 / 1$ \\
\hline Age of diagnosis, $y$ & $15(8-22)$ & $20(15-30)^{*}$ \\
\hline TC at diagnosis, mmol/l & $8.4(7-10)$ & $10.3(8-12)^{\dagger}$ \\
\hline Xanthomas, $n(\%)$ & $7(14.9)$ & $20(30.7)^{\ddagger}$ \\
\hline \multicolumn{3}{|l|}{ Cardiovascular risk factors } \\
\hline Current smoking, $n(\%)$ & $13(27.7)$ & $21(32.3)$ \\
\hline Arterial hypertension, $n(\%)$ & $1(2.1)$ & $10(15.4)^{*}$ \\
\hline \multicolumn{3}{|l|}{ Lipids levels } \\
\hline $\mathrm{TC}, \mathrm{mmol} / \mathrm{L}$ & $5.7(5-7)$ & $6.4(6-7.3)^{\S}$ \\
\hline $\mathrm{TG}, \mathrm{mmol} / \mathrm{L}$ & $0.9(0.7-1.2)$ & $1.1(0.8-1.5)^{\S}$ \\
\hline $\mathrm{HDL}-\mathrm{C}, \mathrm{mmol} / \mathrm{L}$ & $1.2(1-1.5)$ & $1.3(1.2-1.6)$ \\
\hline LDL-C, mmol/L & $3.9(3.6-5)$ & $4.2(3.8-5.4)^{*}$ \\
\hline $\mathrm{ApoB}, \mathrm{mg} / \mathrm{dL}$ & $110.0(101-124)$ & $121.0(105-147)^{8}$ \\
\hline ApoA1, mg/dL & $136.0(127-157)$ & $149.0(132-163)$ \\
\hline $\mathrm{Lp}(\mathrm{a}), \mathrm{mg} / \mathrm{dL}$ & $26.0(12-50)$ & $25.0(9-51)$ \\
\hline \multicolumn{3}{|l|}{ Current lipid treatment } \\
\hline Statin, $n(\%)$ & $35(74.5)$ & $55(84.6)$ \\
\hline Ezetimibe, $n(\%)$ & $7(14.9)$ & $31(47.7)^{\dagger}$ \\
\hline
\end{tabular}

ApoA1, apolipoprotein A1; ApoB, apolipoprotein B; BMI, body mass index; CAC, coronary artery calcium; FH, familial hypercholesterolemia; HDL-C, high-density lipoprotein cholesterol; LDL-C, low-density lipoprotein cholesterol; LDLR, low-density lipoprotein cholesterol receptor; Lp(a), lipoprotein

(a); SBP, systolic blood pressure; TC, total cholesterol; TG, triglycerides.

${ }^{\star} P<.05 ;{ }^{\dagger} P<.001 ;{ }^{\ddagger} P<.01 ;{ }^{\S} P<.02$ vs CAC 0 .

Cholesterol burden at diagnosis was calculated as age $\times$ TC at diagnosis.

Cholesterol burden postdiagnosis was calculated as the sum of one cholesterol per year since diagnosis. Total cholesterol burden is the sum of cholesterol burden at diagnosis and cholesterol burden postdiagnosis.

study, where only $9.9 \%$ of 2832 patients aged 33 to 45 years exhibited coronary calcifications. ${ }^{14}$ Furthermore, the presence of CAC in about a half of patients classified as at low risk by common CVR equations suggest that CAC evaluation could have a real incremental value beyond risk algorithms. However, the final incremental value could only be determined with long-term prospective trial.

Typically, CAC scanning is not used for individuals aged $<45$ years because most atherosclerotic plaques are not calcified in younger individuals, but in our high-risk population, $39 \%$ of individuals with $\mathrm{HeFH}$ aged $<45$ years already had CAC. The large reference MultiEthnic Study of Atherosclerosis (MESA) only enrolled individuals aged $>45$ years, therefore presence of CAC would be a high-risk score for MESA adults aged 45 to 50 years. $^{15}$

The absence of CAC has been associated with a low risk of CHD. ${ }^{16}$ In the Dallas Heart Study cohort of young patients with a family history of CHD, the overall absence of CAC (47\%) was associated to a $0.4 \%$ to $1.9 \%$ CHD rate. However, in this study, the presence of $\mathrm{HeFH}$, often associated with a family history of CHD, was not assessed. ${ }^{8}$ In a cohort of 140 clinically diagnosed $\mathrm{HeFH}$ asymptomatic patients (mean age 52 years, known genetic disorder in $66 \%$ of the cohort, diabetes prevalence $6 \%$ ), only $21 \%$ were found without $\mathrm{CAC}$. They underwent $\mathrm{CT}$ angiography and no plaques were found, whereas $69 \%$ of patients with a CAC score $>400$ exhibited obstructive CAD. ${ }^{17}$

Apart from CAC, some clinical parameters have shown to be useful in $\mathrm{HeFH}$ patients for CVD risk refinement. Among them lipoprotein(a) has been associated with early CHD also in $\mathrm{FH}^{18}$ and can be used for risk reclassification. ${ }^{19}$ Contrarily, while a null mutation has been associated with an increased prevalence of premature CVD and recurrence of CV events compared with a defective LDLR mutation, ${ }^{20}$ no significant associations were found between mutation type and aortic/carotid plaque presence. $^{21}$

Our results in $\mathrm{HeFH}$ with an established genetic diagnosis reinforce the concept of an association between early, 


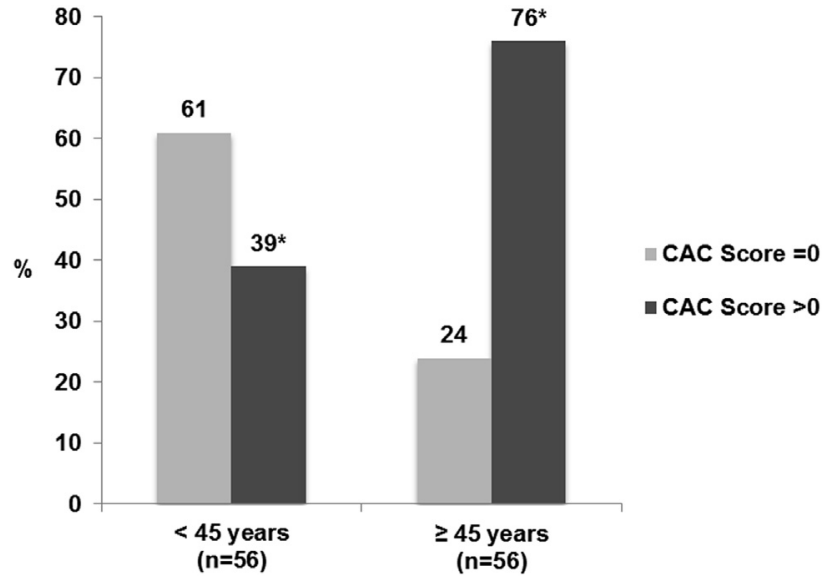

Figure 1 Prevalence of $\mathrm{CAC}$ in patients aged $<45$ and $>45$ years. ${ }^{*} P<.001$ vs absence of CAC. CAC, coronary artery calcium; HeFH, heterozygous familial hypercholesterolemia.

lifelong cholesterol exposure and premature atherosclerosis shown in non-HeFH subjects of the Framingham offsprings cohort. ${ }^{22}$ Here, in HeFH subjects, we showed an independent association between TCB and calcified coronary atherosclerotic burden that expands previous results on arterial stiffening and thickening. ${ }^{23}$ In young patients aged $<45$ years, we report the high prevalence of CAC presence in correlation with the cholesterol burden at diagnosis suggesting a potential role of early exposure to elevated cholesterol levels. The strength of our study is the inclusion of $\mathrm{HeFH}$ who have been genetically diagnosed, early treated, and regularly followed in our unit since diagnosis. This enabled us to limit potential bias in cholesterol burden calculation and to present results in a very well-characterized population.



Figure 2 Cholesterol burden in patients aged $<45$ years (left) and $\geq 45$ years (right) with or without CAC. $* P<.02$; $* * P<.001$ vs absence of CAC. Patients aged $<45$ years: $\mathrm{CAC}=0(n=34)$; CAC $>0(n=22)$. Patients aged $\geq 45$ years: $\mathrm{CAC}=0(n=13)$; $\mathrm{CAC}>0(n=43)$.
Table 3 Multivariate analysis of CAC score determinants

\begin{tabular}{|c|c|c|c|}
\hline & \multicolumn{3}{|c|}{ Calcium score } \\
\hline & $\overline{R^{2}}$ & $\beta$ & $P$ \\
\hline Overall model & 0.29 & & .0001 \\
\hline Gender $($ male $=1)$ & & $1.98 \pm 0.7$ & .005 \\
\hline $\begin{array}{l}\text { Total cholesterol } \\
\text { burden, } \\
\text { mmol-years/L }\end{array}$ & & $0.01 \pm 0.003$ & .0001 \\
\hline $\begin{array}{l}\text { Current smoking } \\
\quad(\text { yes }=1)\end{array}$ & & $0.5 \pm 0.64$ & .42 \\
\hline $\begin{array}{l}\text { Statin treatment } \\
\quad(\text { yes }=1)\end{array}$ & & $0.38 \pm 0.81$ & .64 \\
\hline HDL-C, mmol/L & & $0.1 \pm 0.7$ & .9 \\
\hline $\mathrm{TG}, \mathrm{mmol} / \mathrm{L}$ & & $0.33 \pm 0.5$ & .5 \\
\hline $\mathrm{FPG}, \mathrm{mmol} / \mathrm{L}$ & & $0.29 \pm 0.63$ & .65 \\
\hline $\mathrm{SBP}, \mathrm{mm} \mathrm{Hg}$ & & $-0.002 \pm 0.031$ & .98 \\
\hline
\end{tabular}

FPG, fasting plasma glucose; HDL-C, high-density lipoprotein cholesterol; SBP, systolic blood pressure; TG, triglycerides.

Cholesterol burden at diagnosis can be easily calculated and may be helpful beyond single TC levels to identify higher risk $\mathrm{HeFH}$ patients who could benefit from a more aggressive lipid-lowering treatment (eg, high-dose statin + ezetimibe, PCSK9 inhibitors, and/or lomitapide).

The dCB calculation (TC levels at diagnosis $X$ age at diagnosis) assumes that TC levels are a constant throughout early life, which may raise some doubts. However, during the 27 years of follow-up of the Bogalusa Heart Study, $66.2 \%$ of the dyslipidemic subjects in the 2 highest quintiles for non-HDL-C levels remained in the same quintiles during adulthood. ${ }^{24}$

The early appearance of calcified plaques in $\mathrm{HeFH}$ can be explained by several mechanisms. First, the LDLR itself may have a potential role in determining a higher prevalence of calcifications in young $\mathrm{HeFH}$ patients. A crosstalk between LDLR and LDL-related protein 5/6 may take place that would allow the nuclear translocation of beta-catenin in the osteocyte, determining calcium deposition in the vascular wall. ${ }^{25}$ Our results also confirm previously data published by Borholt-Petersen et al. where no influence of the type of LDLR mutation (null vs defective) was associated with a more severe vascular phenotype. ${ }^{26}$ Statins have been shown to prevent atherosclerotic plaques development but also to enhance their calcifications. ${ }^{27}$ Eighty percent of our patients were under statin treatment: on the one hand, this may have explained the relatively high prevalence of calcified plaques in our younger subgroup of HeFH patients; on the other hand, an early treatment initiation may have accounted for the $61 \%$ prevalence of zero CAC in the younger. However, in the multivariate analysis, statin treatment was not associated with CAC. Novel recommendations suggest, for $\mathrm{HeFH}$, a treatment goal LDL-C $<1.8 \mathrm{mmol} / \mathrm{L}$ for patients at high risk due to the evidence of CVD or a severe FH phenotype ${ }^{28}$ suggestive of a delayed diagnosis and/or treatment. CAC 
scanning could be a useful tool in HeFH patients' upward CVR reclassification, to identify those individuals who could benefit from a statin-ezetimibe combination or PCSK9 antibodies therapy. Moreover, in this age of electronic medical records, a measure of TCB could be generated as a tool for clinicians to identify high-risk individuals who might warrant early and more intensified prevention.

Our study exhibits some limitations. First, it is a crosssectional study on a small genetically selected population. However, it enabled accurate phenotyping and TCB calculation.

The concept of TCB may be considered controversial in FH patients because they are exposed to very high cholesterol levels since birth. However, even in our cohort of genetically classified, early treated, and regularly followed-up $\mathrm{HeFH}$ patients, we were able to observe that treatment initiation has an effect in reducing TCB.

CT angiography, the gold standard for coronary plaque detection, was not performed. Although this may have allowed hypodense noncalcified plaques detection, CT angiography requires contrast injection and a higher radiation exposure. In terms of risk reclassification, it did not lead to an improvement when compared with a model based on standard risk factors and CAC in a registry of asymptomatic non- $\mathrm{HeFH}^{29}$ or $\mathrm{HeFH}$ subjects with other CVR factors. ${ }^{12,17}$ Finally, we did not compare HeFH to a control group. However, we used the same age non-HeFH CARDIA study cohort to compare the prevalence of CAC. Furthermore, validated age- and gender-adjusted nomograms from the MESA were used in which young patients with CAC $>0$ fall in the 75th percentile to postulate that having $\mathrm{CAC}$ aged $<45$ years indicates high CVR. ${ }^{15}$

In conclusion, young asymptomatic $\mathrm{HeFH}$ subjects exhibit early calcified coronary atherosclerosis in association with lifelong exposure to high cholesterol levels. TCB calculation at the time of diagnosis may be useful to identify more severe phenotypes of $\mathrm{HeFH}$ patients who could benefit from a more aggressive lipid-lowering therapy as advocated by recent guidelines. In this accurately selected population of genetically confirmed $\mathrm{HeFH}$ patients, CAC score may therefore contribute to tailor more aggressive LDL-C lowering strategies aiming at reaching LDL-C target.

\section{Acknowledgment}

Authors' contributions: All authors contributed to conception, design, drafting and final revision and approval of the article. A.G., P.G., E.B., and D.R. provided to data collection and analysis; A.C. performed genetic analysis; A.R. analyzed all CT images for CAC score calculation; R.B. provided lipid and biochemical profiling.

Funding sources: This research did not receive any specific grant from funding agencies in the public, commercial, or not-for-profit sectors.

\section{Disclosure}

E.B. declares having received honoraria from AstraZeneca, AMGEN, Genfit, MSD, Sanofi and Regeneron, Unilever, Danone, Aegerion, Chiesi, RottapharmMEDA, Lilly, Ionis-pharmaceuticals; D.R. declares having received honoraria from AMGEN (Research Grant), Sanofi, Novartis, Roche, AMGEN, Daiichi Sankyo, MSD (Fees for lecture/consulting and travel grants). Remaining authors have nothing to disclose.

\section{References}

1. Benn M, Watts GF, Tybjærg-Hansen A, Nordestgaard BG. Mutations causative of familial hypercholesterolaemia: screening of 98098 individuals from the Copenhagen General Population Study estimated a prevalence of 1 in 217. Eur Heart J. 2016;37(17):1384-1394.

2. Nordestgaard BG, Chapman MJ, Humphries SE, et al, for the European Atherosclerosis Society Consensus Panel. Familial hypercholesterolaemia is underdiagnosed and undertreated in the general population: guidance for clinicians to prevent coronary heart disease: consensus statement of the European Atherosclerosis Society. Eur Heart J. 2013;34(45):3478-3490a.

3. Hutter CM, Austin MA, Humphries SE. Familial hypercholesterolemia, peripheral arterial disease, and stroke: a HuGE minireview. Am J Epidemiol. 2004;160(5):430-435.

4. Sniderman AD, Tsimikas S, Fazio S. The severe hypercholesterolemia phenotype: clinical diagnosis, management, and emerging therapies. $J$ Am Coll Cardiol. 2014;63(19):1935-1947.

5. Risk of fatal coronary heart disease in familial hypercholesterolemia. Scientific Steering Committee on behalf of the Simon Broome Register Group. BMJ. 1991;303(6807):893-896.

6. Sharifi M, Rakhit RD, Humphries SE, Nair D. Cardiovascular risk stratification in familial hypercholesterolemia. Heart. 2016;102(13): 1003-1008.

7. Rana JS, Gransar H, Wong ND, et al. Comparative value of coronary artery calcium and multiple blood biomarkers for prognostication of cardiovascular events. Am J Cardiol. 2012;109(10):1449-1453.

8. Paixao ARM, Berry JD, Neeland IJ, et al. Coronary artery calcification and family history of myocardial infarction in the Dallas Heart Study. JACC Cardiovasc Imaging. 2014;7(7):679-686.

9. Agatston AS, Janowitz WR, Hildner FJ, Zusmer NR, Viamonte M, Detrano R. Quantification of coronary artery calcium using ultrafast computed tomography. J Am Coll Cardiol. 1990;15(4):827-832.

10. Schmidt HH, Hill S, Makariou EV, Feuerstein IM, Dugi KA, Hoeg JM. Relation of cholesterol-year score to severity of calcific atherosclerosis and tissue deposition in homozygous familial hypercholesterolemia. Am J Cardiol. 1996;77(8):575-580.

11. Gidding SS, Bookstein LC, Chomka EV. Usefulness of electron beam tomography in adolescents and young adults with heterozygous familial hypercholesterolemia. Circulation. 1998;98(23):2580-2583.

12. Miname MH, Ribeiro MS, Parga Filho J, et al. Evaluation of subclinical atherosclerosis by computed tomography coronary angiography and its association with risk factors in familial hypercholesterolemia. Atherosclerosis. 2010;213(2):486-491.

13. Martin SS, Blaha MJ, Blankstein R, et al. Dyslipidemia, coronary artery calcium, and incident atherosclerotic cardiovascular disease: implications for statin therapy from the multi-ethnic study of atherosclerosis. Circulation. 2014;129(1):77-86.

14. Okwuosa TM, Greenland P, Ning H, Liu K, Lloyd-Jones DM. Yield of screening for coronary artery calcium in early middle-age adults based on the 10-year Framingham Risk Score: the CARDIA study. JACC Cardiovasc Imaging. 2012;5(9):923-930.

15. McClelland RL, Chung H, Detrano R, Post W, Kronmal RA. Distribution of coronary artery calcium by race, gender, and age: results from 
the Multi-Ethnic Study of Atherosclerosis (MESA). Circulation. 2006; 113(1):30-37.

16. Nasir K, Budoff MJ, Wong ND, et al. Family history of premature coronary heart disease and coronary artery calcification: Multi-Ethnic Study of Atherosclerosis (MESA). Circulation. 2007;116(6):619-626.

17. Neefjes LA, Ten Kate G-JR, Alexia R, et al. Accelerated subclinical coronary atherosclerosis in patients with familial hypercholesterolemia. Atherosclerosis. 2011;219(2):721-727.

18. Alonso R, Andres E, Mata N, et al, for the SAFEHEART Investigators. Lipoprotein(a) levels in familial hypercholesterolemia: an important predictor of cardiovascular disease independent of the type of LDL receptor mutation. J Am Coll Cardiol. 2014;63(19):1982-1989.

19. Nordestgaard BG, Chapman MJ, Ray K, et al, for the European Atherosclerosis Society Consensus Panel. Lipoprotein(a) as a cardiovascular risk factor: current status. Eur Heart J. 2010;31(23): 2844-2853.

20. Alonso R, Mata N, Castillo S, et al, on behalf of the Spanish Familial Hypercholesterolaemia Group. Cardiovascular disease in familial hypercholesterolaemia: influence of low-density lipoprotein receptor mutation type and classic risk factors. Atherosclerosis. 2008;200(2): 315-321.

21. Caballero P, Alonso R, Rosado P, et al. Detection of subclinical atherosclerosis in familial hypercholesterolemia using non-invasive imaging modalities. Atherosclerosis. 2012;222(2):468-472.

22. Navar-Boggan AM, Peterson ED, D'Agostino RB, Neely B, Sniderman AD, Pencina MJ. Hyperlipidemia in early adulthood increases long-term risk of coronary heart disease. Circulation. 2015; 131(5):451-458.
23. Cheng HM, Ye ZX, Chiou KR, Lin SJ, Charng MJ. Vascular stiffness in familial hypercholesterolaemia is associated with C-reactive protein and cholesterol burden. Eur J Clin Invest. 2007;37(3):197-206.

24. Srinivasan SR, Frontini MG, Xu J, Berenson GS. Utility of childhood non-high-density lipoprotein cholesterol levels in predicting adult dyslipidemia and other cardiovascular risks: the Bogalusa Heart Study. Pediatrics. 2006;118(1):201-206.

25. Pugliese G, Iacobini C, Blasetti Fantauzzi C, Menini S. The dark and bright side of atherosclerotic calcification. Atherosclerosis. 2015; 238(2):220-230.

26. Brorholt-Petersen JU, Jensen HK, Jensen JM, et al. LDL receptor mutation genotype and vascular disease phenotype in heterozygous familial hypercholesterolaemia. Clin Genet. 2002;61(6):408-415.

27. Puri R, Nicholls SJ, Shao M, et al. Impact of statins on serial coronary calcification during atheroma progression and regression. J Am Coll Cardiol. 2015;65(13):1273-1282.

28. Santos RD, Gidding SS, Hegele RA, et al, International Atherosclerosis Society Severe Familial Hypercholesterolemia Panel. Defining severe familial hypercholesterolaemia and the implications for clinical management: a consensus statement from the International Atherosclerosis Society Severe Familial Hypercholesterolemia Panel. Lancet Diabetes Endocrinol. 2016;4(10):850-861.

29. Cho I, Chang H-J, Ó Hartaigh B, et al. Incremental prognostic utility of coronary CT angiography for asymptomatic patients based upon extent and severity of coronary artery calcium: results from the COronary CT Angiography EvaluatioN For Clinical Outcomes InteRnational Multicenter (CONFIRM) study. Eur Heart J. 2015;36(8): 501-508. 


\section{Appendix}

Supplementary Table 1 Univariate analysis of determinants of total CB, CB at diagnosis and postdiagnosis

\begin{tabular}{|c|c|c|c|c|c|c|}
\hline & \multicolumn{2}{|l|}{ DLCN } & \multicolumn{2}{|c|}{ Simon-Broome } & \multicolumn{2}{|c|}{ MEDPED } \\
\hline & $\overline{R^{2}}$ & $P$ & $\overline{R^{2}}$ & $P$ & $\overline{R^{2}}$ & $P$ \\
\hline Total cholesterol burden & 0.625 & .001 & 0.645 & .000 & 0.603 & .041 \\
\hline Diagnosis cholesterol burden & 0.351 & .043 & 0.327 & .629 & 0.331 & .391 \\
\hline Postdiagnosis cholesterol burden & 0.123 & .7 & 0.231 & .000 & 0.176 & .009 \\
\hline
\end{tabular}

CB, cholesterol burden; DLCN, Dutch Lipid Clinic Network; MEDPED, Make Early Diagnosis to Prevent Early Deaths.

Supplementary Table 2 Number of subjects for each cardiovascular risk score class, according to presence/absence and intensity of CAC

\begin{tabular}{|c|c|c|c|c|c|c|c|c|c|c|c|c|}
\hline & \multicolumn{4}{|l|}{ Score } & \multicolumn{3}{|c|}{ Framingham } & \multicolumn{5}{|l|}{ ASCVD } \\
\hline & $\begin{array}{l}\text { Low } \\
(<1 \%)\end{array}$ & $\begin{array}{l}\text { Moderate } \\
(1 \%-4.9 \%)\end{array}$ & $\begin{array}{l}\text { High } \\
(\geq 5 \%)\end{array}$ & Total & $\begin{array}{l}\text { Low } \\
(<10 \%)\end{array}$ & $\begin{array}{l}\text { Intermediate } \\
(10 \%-19.9 \%)\end{array}$ & $\begin{array}{l}\text { High } \\
(\geq 20 \%)\end{array}$ & Total & $\begin{array}{l}\text { Low } \\
(<5 \%)\end{array}$ & $\begin{array}{l}\text { Intermediate } \\
(5 \%-7.49 \%)\end{array}$ & $\begin{array}{l}\text { High } \\
(\geq 7.5 \%)\end{array}$ & Total \\
\hline \multicolumn{13}{|l|}{ Presence of CAC } \\
\hline CAC $0, n$ & 40 & 8 & 0 & 48 & 46 & 1 & 1 & 48 & 41 & 7 & 0 & 48 \\
\hline $\mathrm{CAC}>0, n$ & 31 & 33 & 0 & 64 & 50 & 10 & 4 & 64 & 44 & 8 & 12 & 64 \\
\hline Total & 71 & 41 & 0 & $112^{*}$ & 94 & 11 & 5 & $112^{\dagger}$ & 85 & 15 & 12 & $112^{\ddagger}$ \\
\hline \multicolumn{13}{|l|}{ Intensity of CAC } \\
\hline CAC $0, n$ & 49 & 9 & 0 & 48 & 46 & 1 & 1 & 48 & 41 & 7 & 0 & 48 \\
\hline CAC $1-100, n$ & 19 & 13 & 0 & 32 & 27 & 4 & 1 & 32 & 26 & 3 & 3 & 32 \\
\hline $\mathrm{CAC}>100, n$ & 12 & 20 & 0 & 32 & 23 & 6 & 3 & 32 & 18 & 5 & 9 & 32 \\
\hline Total & 71 & 41 & 0 & $112^{*}$ & 96 & 11 & 5 & 112 & 85 & 15 & 12 & $112^{\S}$ \\
\hline
\end{tabular}

ASCVD, atherosclerotic cardiovascular disease; CAC, coronary artery calcification.

Chi-squared test: ${ }^{\star} P=.000 ;{ }^{\dagger} P=.03 ;{ }^{\ddagger} P=.002 ;{ }^{\S} P=.006$. 
Supplementary Table 3 Number of HeFH subjects in the under 45 subgroup for each cardiovascular risk score class, according to presence or absence and intensity of CAC

\begin{tabular}{|c|c|c|c|c|c|c|c|c|c|c|c|}
\hline Score & & & & Framingh & am & & ASCVD & & & & \\
\hline $\begin{array}{l}\text { Low } \\
(<1 \%)\end{array}$ & $\begin{array}{l}\text { Moderate } \\
(1 \%-4.9 \%)\end{array}$ & $\begin{array}{l}\text { High } \\
(\geq 5 \%)\end{array}$ & Total & $\begin{array}{l}\text { Low } \\
(<10 \%)\end{array}$ & $\begin{array}{l}\text { Intermediate } \\
(10 \%-19.9 \%)\end{array}$ & $\begin{array}{l}\text { High } \\
(\geq 20 \%)\end{array}$ & Total & $\begin{array}{l}\text { Low } \\
(<5 \%)\end{array}$ & $\begin{array}{l}\text { Intermediate } \\
(5 \%-7.49 \%)\end{array}$ & $\begin{array}{l}\text { High } \\
(\geq 7.5 \%)\end{array}$ & Total \\
\hline
\end{tabular}

Presence of CAC

\section{CAC $0, n \quad 31$}

$\mathrm{CAC}>0, n \quad 18$

Total

Intensity of CAC

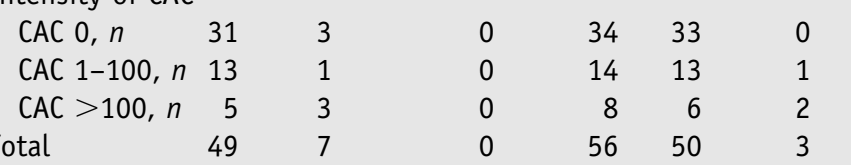

1

1
0
1

$34 \quad 31$

$22 \quad 20$

$56 \quad 51$

3
2
5

0

0

34

1

$\begin{array}{rrrr}1 & 34 & 31 & 3 \\ 0 & 14 & 14 & 0 \\ 0 & 8 & 6 & 2 \\ 1 & 56^{*} & 51 & 5\end{array}$

\begin{tabular}{rr}
0 & 34 \\
0 & 14 \\
0 & 8 \\
0 & 56 \\
\hline
\end{tabular}

ASCVD, atherosclerotic cardiovascular disease; CAC, coronary artery calcification.

Chi-squared test: ${ }^{*} P=.03$. 